cells of undetermined significance (approximates to borderline change $)^{4}$; others are evaluating this but believe that testing has limited potential in triaging low grade squamous intraepithelial lesions (approximates to mild dyskaryosis). ${ }^{5}$ We found an overall test sensitivity and specificity of $86 \%$ and $76 \%$ for 75 subjects with borderline smears, $94 \%$ and $39 \%$ for 117 with mild dyskaryosis, and $95 \%$ and $54 \%$ for 141 with both smear types $(1 \mathrm{pg} / \mathrm{ml})$. We welcome the NHS pilot scheme while advising caution in the clinical use of testing for human papillomavirus, especially at a single point in time.

We thank nursing and medical colleagues at the colposcopy clinic for their assistance.

Contributors: GR had the idea for the study and reviewed the histology. NH performed human papillomavirus testing, wrote the paper, and will act as guarantor. All the authors were clinically involved in carrying out the study and contributed to the final version of the paper.
Funding: The Royal Infirmary of Edinburgh Endowment Fund. Abbott Laboratories kindly provided human papillomavirus testing kits at a discount.

Competing interests: GR and NH have been sponsored by Digene Diagnostics to attend several conferences.

1 Cuzick J, Sasieni P, Davies P, Adams J, Normand C, Frater A, et al. A systematic review of the role of human papillomavirus testing within a cervical screening programme. Health Technol Assess 1999;3 (14)

2 Cuzick J, Beverley E, Ho L, Terry G, Sapper H, Mielzynska I, et al. HPV testing in primary screening of older women. Br J Cancer 1999:81:554-8. E. Where's the high-grade che minimally abnormal Papanicolaou diagnoses. Obstet Gynecol 1998;91:973-6.

4 Manos MM, Kinney WK, Hurley LB, Sherman ME, Shieh-Ngai J, Kurman $\mathrm{RJ}$, et al. Identifying women with cervical neoplasia: using human papillomavirus DNA testing for equivocal Papanicolaou results. JAMA 1999;281:1605-10.

5 The Atypical Squamous Cells of Undetermined Significance/Low-Grade Squamous Intraepithelial Lesions Triage Study (ALTS) Group. Human papillomavirus testing for triage of women with cytologic evidence of low-grade squamous intraepithelial lesions: baseline data from a randomized trial. J Natl Cancer Inst 2000;92:397-402.

(Accepted 11 October 2000)

\title{
Do obstetric complications explain high caesarean section rates among women over 30 ? A retrospective analysis
}

\author{
Jacqueline S Bell, Doris M Campbell, Wendy J Graham, Gillian C Penney, Mandy Ryan, Marion H Hall
}

Dugald Baird

Centre for Research in Women's Health,

Department of

Obstetrics and

Gynaecology,

Aberdeen Maternity

Hospital, Aberdeen

AB25 2ZL

Jacqueline S Bell

research fellow

Doris M Campbell

senior lecturer

Wendy J Graham

professor

Gillian C Penney

senior lecturer

Marion H Hall

consultant

obstetrician

Health Economics

Research Unit,

University of

Aberdeen,

Aberdeen

AB25 2ZD

Mandy Ryan

Medical Research

Council senior fellow

Correspondence to:

J S Bell

j.bell@abdn.ac.uk

BMJ 2001;322:894-5

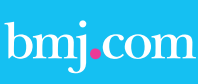

Figure showing odds ratios for delivery by

caesarean section

in women with no

history of such

sections appears on

the BMJ's website
As a growing proportion of women delay childbearing into their later reproductive years, the risks and costs associated with advancing maternal age become increasingly important. Extensive evidence shows that both obstetric interventions and obstetric complications are more common among older women, ${ }^{1}$ and it is often assumed that the interventions are a consequence of the complications. Delivery by caesarean section is one such intervention that is associated with maternal age and is of importance for public health. The extent to which the association is explained by obstetric complications is, however, not known. Martel et al showed that an association between maternal age and rates for primary caesarean section persisted after adjustment for induction of labour, epidural anaesthesia, meconium stained amniotic fluid, and fetal distress. ${ }^{2}$ We aimed to build on this finding by considering a greater number of obstetric complications in a much larger population and with more detailed records.

\section{Methods and results}

We obtained our information from the Aberdeen Maternal and Neonatal Databank for all singleton deliveries to city residents aged at least 20 years during 1988-97; totalling 23806 deliveries. ${ }^{3}$ We used logistic regression to obtain crude odds ratios for delivery by caesarean section among older women (age categories 30-31, 32-33, 34-35, 36-37, 38-39, and 40 and over) compared with a reference group of women aged 20-29 years. Primiparous and multiparous women were analysed separately, as were elective and emergency caesarean sections. We investigated the potential confounders of the association between age and outcome, and we also checked for any evidence of effect modification with the same variables-maternal sociodemographic characteristics and obstetric history.
We selected the obstetric complications and interventions associated with a higher probability of caesarean section, which might explain the association with age (see figure on web). Using multivariate logistic regression we adjusted the crude odds ratios for these variables, also controlling for any identified confounders and stratifying by effect modifiers.

The association between maternal age and caesarean section varied depending on how the baby presented at delivery and whether a woman had previously had a caesarean. Among women who had not previously had a caesarean section and whose babies presented normally at delivery there was a strong and consistent relation between maternal age and delivery by caesarean section that remained after controlling for relevant obstetric complications and identified confounders (see figure on web). Among women who had had a previous caesarean section or whose babies presented abnormally the association between maternal age and both elective and emergency sections was greatly reduced (results not shown).

\section{Comment}

The observed relation between maternal age and caesarean section cannot be explained by the obstetric complications we considered. They add to previous findings by including greater numbers of obstetric complications and deliveries in the analysis. This raises the question of why rates for caesarean section are high among older mothers, and whether they may be explained by physiological or other factors we have been unable to control for. Medical causes that have been suggested include reduced uterine function and pelvic compliance among older women. ${ }^{4}$ However we expected that length of labour would act as a proxy for these factors in our analysis. Many authors have identi- 
fied physician and maternal preference in the higher section rates among older women, ${ }^{15}$ and our results would support this speculation. Further investigation is needed into women's views about increased intervention, the variation in rates for caesarean section among obstetricians, and how maternal age influences both of these factors.

This project was funded by the Chief Scientist Office of the Scottish Executive; the executive accepts no responsibility for the information provided or the views expressed.

Contributors: JSB analysed the data and conducted the preliminary interpretation of the results; she was responsible for drafting and revising the paper. DMC, WJG, MHH, GCP, and MR designed the study, secured the funding for the project, and advised throughout on the conduct and interpretation of the analysis. WJG identified the need for the study. All authors helped revise the paper and will act as guarantors.

Competing interests: None declared.

1 Berkowitz GS, Skovron ML, Lapinski RH, Berkowitz RL. Delayed childbearing and the outcome of pregnancy. N Engl J Med 1990;322: 659-64

2 Martel M, Wacholder S, Lippman A, Brohan J, Hamilton E. Maternal age and primary cesarean section rates: a multivariate analysis. Am J Obstet Gynecol 1987;156:305-8.

3 Samphier M, Thompson B. The Aberdeen Maternal and Neonatal Databank. In: Mednick SA, Baert AE, eds. Prospective longitudinal research. London: Oxford University Press, 1981.

4 Rosenthal AN, Paterson-Brown S. Is there an incremental rise in the risk of obstetric intervention with increasing maternal age? BrJ Obstetr Gynaecol 1998; 105:1064-9.

5 Leitch CR, Walker IJ. The rise in caesarean section rate: the same indications but a lower threshold. Br J Obstetr Gynaecol 1998;105:621-6.

(Accepted 1 December 2000)

\title{
Take home naloxone and the prevention of deaths from opiate overdose: two pilot schemes
}

\author{
Kerstin Dettmer, Bill Saunders, John Strang
}

Doctors routinely give naloxone during emergency resuscitation after opiate overdose. The distribution of naloxone to opiate addicts has recently been addressed, ${ }^{1-4}$ and a survey of drug users shows extensive support for the provision of supplies to take away. ${ }^{4} \mathrm{We}$ present the preliminary results of two pilot schemes to provide take home naloxone to opiate users.

\section{Methods and results}

\section{The Berlin project}

In January 1999 drug users in Berlin were given naloxone to take home. Opiate misusers attending a healthcare project (operating from a mobile van or ambulance) were offered training in emergency resuscitation after overdose, provided with naloxone (two $400 \mu \mathrm{g}$ ampoules), needles, syringes, an emergency handbook, and information on naloxone. They were asked to report on any use of the drug. After 16 months, 124 opiate misusers had received training in resuscitation and were provided with supplies of naloxone to take away; 40 reported back, with 22 having given emergency naloxone (two on two occasions, one on three, and one on four).

The methods of administration were diverse. Resuscitation occurred both at home $(17 ; 59 \%)$ and outdoors (parks, public restrooms) (11; 38\%). In 10 instances the individual was unknown to the person resuscitating him or her $(35 \%)$. Naloxone was given intramuscularly (14 instances; 48\%), intravenously (13; $45 \%)$, and subcutaneously (2; 7\%). One ampoule was the usual dose given $(22 ; 76 \%)$. Half an ampoule was given to four people (14\%) and both ampoules to three $(10 \%)$. In $10(34 \%)$ instances naloxone provoked a sudden onset of opiate withdrawal; no other side effects were reported. An ambulance was called for nine (31\%). All 29 people recovered. Naloxone was judged appropriate in $26(90 \%)$ cases, of uncertain benefit (no life threatening situation) in two (7\%), and pointless in one (cocaine overdose). More risky consumption as a result of the availability of naloxone was not reported.

\section{Case 1 (Berlin) \\ "Three days ago, I was walking along the canal with a friend of mine. We saw a guy lying on the ground, with two people trying to help him-they were trying to help him breathe by mouth to mouth. When we ran over to them, we could tell it wasn't really working. The guy was blue in the face and hardly breathing any more. I could barely feel his pulse. Right away I gave him one ampoule of naloxone-I didn't think I could find a vein so I just shot it real slow into his upper arm. We tried to give him CPR and we called 911. Then the guy started to wake up and he started to breathe and shake a little bit. He was so thankful, he wanted to give me 50 Marks, but I wouldn't take it. When the medics came I told them I had given him the naloxone. The medics said 'Wow! So you guys have even got naloxone now?' But he thought it was great. He said we had probably just saved the guy's life." The ambulance staff then took the overdose victim to hospital for further observation.}

\section{The Jersey project}

From October 1998 over the next 16 months naloxone (one minijet ready filled with $800 \mu \mathrm{g}$ naloxone) was provided to 101 drug misusers in contact with local drug services, with instructions on intramuscular administration and the wider principles of resuscitation from overdose and recovery. Five instances of resuscitation using naloxone were reported, and all fully recovered. No adverse consequences, other than withdrawal symptoms, were reported.

\section{Comment}

This is the first published report of lives saved directly by the provision of take home naloxone. The drug was generally used appropriately. In only one case out of 34 was its use inappropriate, with two of doubtful benefit. No unexpected adverse effects were reported.

Ready prepared syringes of naloxone typically cost $£ 3.30-6.70$ per $400 \mu \mathrm{g}$. Since 10\% of distributed doses
Fixpunkt e V Mobilix, 10967 Berlin, Germany Kerstin Dettmer project director

Colleagues in the Berlin project are listed at the end of the paper

Alcohol and Drug Service, Gloucester Lodge, St Saviour, Jersey, Channel Islands JE2 7LB

Bill Saunders director

National Addiction Centre, Institute of Psychiatry and the Maudsley Hospital, London SE5 8AF John Strang

director

Correspondence to J Strang j.strang@iop.kcl. ac.uk

BMJ 2001;322:895-6 